\title{
Physical Activity, Fine Manual Dexterity and a Coach's Self-Efficacy in a Physical Activity Program for Older Persons Living in Residential Care Facilities
}

\author{
Monica Emma Liubicich ${ }^{1}$, Daniele Magistro ${ }^{1}$, Filippo Candela ${ }^{2}$, \\ Emanuela Rabaglietti $^{1,2}$, Silvia Ciairano ${ }^{1,2}$ \\ ${ }^{1}$ University Interfaculty School in Motor Science (SUISM), Research Center in Motor and Sport Science, \\ University of Turin, Turin, Italy \\ ${ }^{2}$ Department of Psychology, University of Turin, Turin, Italy \\ Email: monica.liubicich@unito.it
}

Received February $2^{\text {nd }}, 2012$; revised March $9^{\text {th }}, 2012$; accepted April $11^{\text {th }}, 2012$

\begin{abstract}
This study aimed at assessing the efficacy of a physical activity intervention on a group of older elderly individuals living in residential care facilities, in terms of the functionality of their upper limbs, hands, and fingers. It also aimed at determining if the coaches' level of self-efficacy can contribute to the efficacy of the physical activity program. The project involved 44 institutionalized older persons: Their mean age was $84.3(\mathrm{SD}=7.4)$ in the experimental group and $85(\mathrm{SD}=6.6)$ in the control group; they were all self-sufficient. Seven female coaches, with degrees in physical education and an average age of 29 (SD = 4.4), conducted the physical activity program for 16 weeks. The participants were pre- and post-tested for hand and finger strength with dynamometers. The coaches' level of perceived self-efficacy was assessed through a self-reported questionnaire (Caprara, 2010). The results obtained by using non-parametric statistical techniques, due to the small sample size, confirmed that the physical activity intervention had positive effects on the fine manual dexterity of the elderly in the experimental group, and the high level of self-efficacy perceived by the coaches influenced the effects of the physical training. The results emphasize the importance of setting realistic objectives, and prove that the choice and training of coaches is fundamental for physical exercise practiced in a condition of frailty, such as that of older people living in residential care facilities.
\end{abstract}

Keywords: Elderly; Physical Activity; Coach; Self-Efficacy

\section{Introduction}

There are a growing number of elderly individuals in our society (World Health Organization, 2002). Generally speaking, a longer lifespan may be associated with an increase in disabilities in the frailest bracket of the population (WHO, 2002; Hardy, Dubin, Holford, \& Gill, 2005; Stenzelius, Westergreen, Thorneman, \& Rahm Hallberg, 2005). In fact, many older people have grave difficulties using objects in their daily life because they have lost a certain amount of manual dexterity. For instance, they may have difficulties in using small objects, in opening and closing coffee machines, getting dressed and so on. These difficulties may strongly negatively affect their activities of daily living (ADL), with negative cascade effects over several fields of application, such as inviting friends to one's home or going out to meet them. Thus, given the role of fine manual dexterity on activities of daily living we need to explore the most convenient way to maintain this and prevent its loss of functioning. The present study tackles this issue.

Manual dexterity is the ability to execute controlled, accurate, and coordinated movements using the hands and fingers in daily activities such as writing, chopping, and knitting. Various studies have shown that both fine manual dexterity (Hackel, Wolfe, Bang, \& Canfield, 1992; Mathiowetz, Weber, Kashman, $\&$ Volland, 1985) and motor coordination decline with age
(Desrosiers, Hebert, Bravo, \& Dutil, 1995). This decline can be attributed to neuromuscular changes, to the decrease in the number and increase in size of motor neurons, and changes in the contractile capacity of muscles (Vaillancourt, Larsson, \& Newell, 2003; Martin, Sale, \& Semmler, 2005).

Moreover, some studies have highlighted age-related changes in finger strength and in the independent and synergistic interaction of fingers (Oliveira, Shim, Loss, Petersen, \& Clarke, 2006; Potter, Kent, Lindstrom, \& Lazarus, 2006; Shinohara, Latash, \& Zatsiorsky, 2003).

Some research has also proven that there is a strong connection between hand strength and health problems, disability, and mortality (Rantanen, Volpato, Ferrucci, Heikkinen, Fried, \& Guralnik, 2003; Snih, Markides, Ottenbacher, \& Raij, 2004). As previously said, the loss of fine manual dexterity has severe consequences on the elderly's autonomy in activities of daily living. In particular, the changes in fine manual dexterity seem to limit the ability to perform basic tasks such as moving objects, getting dressed, eating, and writing, and may hence affect quality of life Scherder, Dekker, \& Eggermont, 2008; Topinkovà, 2008). Specifically, the decrease in finger strength, which represents an important parameter related to hand functioning, may have a significant impact on these basic daily abilities (Carmeli, Patish, \& Coleman, 2003).

In addition, the loss of autonomy in activities of daily living, 
whether related to fine manual mobility and/or to other mobility problems, may cause a series of negative consequences such as the loss of independence (Paterson, Govindasamy, Vidmar, Cunningham, \& Koval, 2004; Huang, Perera, VanSwearingen, \& Studenski, 2010), institutionalization (Bharucha, Pandav, Shen, Dodge, \& Ganguli, 2004) and mortality (Millàn-Calenti, Tubio, Pita-Fernandez, Gonzales-Abràldes, Lorenzo, FernàndezArruty, \& Maseda, 2010). These negative consequences may lead to a further worsening of the general health condition and the quality of life of the elderly, limiting their self-sufficiency or forcing them to live in residential care facilities (Guralnik, Alecxih, Branch, \& Wiener, 2002; Lubitz, Cai, Kramarow, \& Lentzner, 2003).

Thus, since we know that the loss of manual dexterity is associated with a loss of autonomy and a worsening quality of life of the elderly, it is important to intervene regarding this physical ability (Scherder, 2008; Taekema, Gussekloo, Maier, Westendorp, \& De Craen, 2010). For this reason, specific intervention programs that improve and/or maintain the stability of fine manual dexterity, contributing to the maintenance of the elderly's self-sufficiency, can be an important resource: among all possible intervention programs we can apply in this kind of context, physical activity programs appear to be particularly interesting. We already know that physical activity can protect older people who are in a situation of physical and psychosocial frailty, playing an important role in terms of mobility function and preserving the skills they need to retain a good level of autonomy. Several studies have confirmed the positive effects of physical activity programs on motor functions in independent elderly individuals aged between 65 and 75 who are living in their own homes (among others, see: Hauer, Becker, \& Beyer, 2006; van der Bij, Laurant, \& Wensing, 2002). Specifically, recent studies have shown that physical activity can improve the strength of the hands and fingers (Baker, Atlantis, \& Fiatarone Singh, 2007; Keogh, Morrison, \& Barrett, 2007). With respect to the very elderly, the guidelines of the American College of Sports Medicine (ACSM, 2000) state that physical activity programs designed for the guests of residential care facilities should focus on the objective of preserving the skills that are functional to their independence, educating the participants towards maintaining an active lifestyle through individual psychophysical wellbeing. In fact, some research has shown that older elderly individuals benefit from physical activity in terms of their overall wellbeing and a decreased risk of developing illnesses that might lead to disability (among others, see: Rejeski \& Mihalko 2001; Peri, Kerse, Robinson, Parsons, Parsons, \& Latham, 2008; Malbut, Dinan, \& Young, 2002; Jessup, Horne, Vishen, \& Wheeler, 2008). Therefore, a specific physical activity intervention designed for the maintenance of autonomy in the elderly of residential care facilities can be an important resource because it helps the elderly maintain their residual physical abilities, also contributing to a better psychological condition (Kasser \& Ryan, 1999) and limiting the risk of mortality (Blair, 1999). However, few studies have analyzed physical activity programs designed for the guests of residential care facilities, i.e. the frailest bracket of the population which runs the highest risk of losing its autonomy.

We know that some physical activity interventions work better than others, but the reasons behind this have rarely been investigated (Booth, Owen, Bauman, Clavisi, \& Leslie, 2000). The "oldest old" often decide to participate in physical activity because they want to preserve the skills that allow them to be independent (Fried, Ferrucci, Darer, Williamson, \& Andreson, 2004; Gill, Baker, Gottschalk, Peduzzi, Allore, \& Van Ness, 2004). In particular, the elderly in residential care facilities need to be highly motivated, supported by those around them, able to appreciate the advantages of physical activity, and have a positive attitude towards training (Wilcox, Tudor-Locke, \& Ainsworth, 2002). Elderly people need to be supported, to have a guide who shows them how to be active (Dye \& Wilcox, 2006), and helps them in training exercises, which must have achievable goals. For this reason, the role of trained professionals who conduct physical activity programs can play a crucial role not only in the elderly's decision to take part in a physical activity program but also in their determination to participate actively and consistently, which might help in achieving the set goals.

The efficacy of trained professionals depends on their own self-efficacy regarding their work: according to Bandura (1997), self-efficacy is defined as "the belief in one's capabilities to organize and execute the courses of action required to manage prospective situations" (Bandura, 1997: p. 2). The importance of self-efficacy has been confirmed by various studies that have investigated the role of teachers' self-efficacy in an educational context (Rivkin, Hanushek, \& Kain, 2005; Pianta \& Stuhlman, 2004). The perception of a teacher's self-efficacy has been defined as the level of ability the teacher thinks he/she has to influence the performance and learning abilities of his/her students, promoting learning, motivation and autonomy, and dealing successfully with the work environment and decisions related to work objectives (Bandura, 1997). Many studies have highlighted that a high level of teacher self-efficacy is associated with support to students (Jina, 2002), students' academic achievements (Caprara, Barbaranelli, Steca, \& Malone, 2006; Ross, 1992) and also with the use of efficient group management strategies (Gordon, 2001). These results are similar to those of some of our previous studies which demonstrated that a physiotherapist's high level of self-efficacy is associated with the improved movement abilities of injured individuals (Rabaglietti, Roggero, Mosca, Barberis, \& Ciairano, 2003). Thus, the self-efficacy beliefs of professionals who work with specific people (i.e. students, athletes) seem to have an important role on the effectiveness of each specific intervention.

Despite these results, to our knowledge, no attention has been paid to the role of the professionals conducting physical activity sessions within a complex learning context, such as that of residential care facilities for the elderly. This is more important considering instructors work with one of the frailest segments of the population, the institutionalized elderly. This study is aimed at addressing these lacks.

\section{Research Aims}

The present study represents a continuation of our previous research, which demonstrated the positive effects of physical training on an Italian sample of older people in residential care facilities, in relation to both psychological (Ciairano, Liubicich, \& Rabaglietti, 2010) and motor aspects (Liubicich, Magistro, Candela, Rabaglietti, \& Ciairano, 2012). We continued investigating the effects of physical activity on the elderly population, trying to provide a more comprehensive description of the phenomenon.

In this study, we focus on upper limb motor function and we try to determine if the physical activity program offered to our 
participants affected both right and left hand strength and thumb-index and index-thumb pinch. Moreover, we wish to ascertain if the effects were moderated by the activity coaches' perception of their own self-efficacy.

Our objectives can be summarized by the following research questions:

1) Did participation in the physical activity program have an effect on right and left hand strength, the right and left thumb-index and index-thumb pinch of the elderly?

2) Are the effects of the physical activity program on hand strength and finger pinch moderated by the perception of the activity coaches' self-efficacy?

In line with recent studies (Baker et al., 2007; Keogh et al., 2007), we hypothesize that a physical activity program has a positive effect on upper limb motor skills, specifically on hand and finger strength. Also, we hypothesize that the coaches' self-efficacy can be interpreted as a moderator effect: In fact, given the important role of the self-efficacy of professional workers (Caprara et al., 2006; Jina, 2002; Rabaglietti et al., 2003), we posit that those who participated in activities conducted by coaches possessing a high level of perceived selfefficacy enjoyed greater positive effects on their motor skills than the elderly who had low self-efficacy instructors.

\section{Study Design and Methods}

The intervention was introduced in two Piedmont Region residential care facilities in northern Italy, and another residential care facility also in Piedmont Region was used as control group: Currently, more than 5,000 older people of the Piedmont Region live in residential care facilities (Banchero, 2009). First, from the list offered by the Health Office of the Piedmont Region, we selected 30 facilities that have similar features in terms of accordance with the National Health Service, number and typology of guests (range from 80 to 120), intermediate social and economic conditions of the guests (all the guests in these facilities are requested to pay even a small amount for the care they receive), and services offered to the guests (presence of on-site emergency services, healthcare operators, physiotherapists, and psychologists). The facilities that were selected accommodate both self-sufficient older people (i.e., individuals who can walk, eat, and use the bathroom independently) and dependent older people (requiring assistance in basic activities of daily living), even if at this stage we are especially interested non self-sufficient older people. The facilities are both public and private institutions, but even the private institutions have the same standards as public facilities because they are linked to the Public Health Service through a funding agreement.

Second, we randomly selected four of these facilities from the list and all of them agreed to participate in the study; however, we needed to exclude one facility because after a preliminary investigation with the director we found that we were unlikely to find enough seniors who would fulfill all three inclusion criteria (see participant requirements below) in order to create a physical activity group (we need at least $4-5$ participants). Then, we assigned the two remaining facilities to the experimental condition and one to the control condition.

\section{Participants}

The individuals in both the intervention and the control group were selected by the director of the residential care facil- ity, a trained physician, from among all the elderly people living in the facility. The three criteria for inclusion were: 1) self-sufficiency (see above), 2) absence of serious chronic and/or acute diseases, and 3) intact cognitive functions, which were directly verified by the researchers. The Mini Mental Test (Folstein, Folstein, \& McHugh, 1975) was used to evaluate cognitive functions, and all the older people reached or exceeded the minimum score of 23 . The participants were informed that participation in the study was voluntary and confidential. All the selected elderly agreed to participate and gave their informed consent, in accordance with Italian law and the ethical code of the Association of Italian Psychologists (AIP, 1997).

The sample was comprised of 44 people, $16(36 \%)$ of who were males ( 2 in the control group and 14 in the experimental groups) and 28 (64\%) females ( 9 in the control group and 19 in the experimental groups). We did not find any differences between the experimental and control group $(\chi=2.1$, d.f. $=1, p$ $=.27)$. The mean age was 85 for the control group $(\mathrm{SD}=6.6)$, and $84.26(\mathrm{SD}=7.4)$ for the experimental group $(\mathrm{t}$-test $=-.34$ d.f. $=41, p=.73)$. All the participants lived permanently in the residential care facilities. With regards to marriage status, the majority $(\mathrm{N}=26)$ were widows/widowers or married $(\mathrm{N}=8)$, while others had never married $(\mathrm{N}=7)$ or were divorced $(\mathrm{N}=$ $3)$ : No differences were found between the experimental and control groups $(\chi=3.7$, d.f. $=3, p=.29)$. In terms of education, two levels were considered: "low", corresponding to compulsory education (only primary school) and "high", corresponding to additional non-compulsory education (more than primary school): Also, we did not find significant differences between the two groups $(\chi=2.1$, d.f. $=1, p=.64)$. The average level of education of the participants was in line with that of the age-matched national population (National Institute of Statistics, 2006; Costa, Migliardi, \& Gnavi, 2006). In fact, $75 \%$ of the participants had received only a compulsory education, similar to about $70 \%$ of the national population. Former occupations were divided into manual $(\mathrm{N}=31)$ and non-manual labor $(\mathrm{N}=$ $13)$ and there were no differences in this regard between the experimental and control groups $(\chi=3.2$, d.f. $=1, p=.35)$. With regards to previous participation in organized exercise or sporting activities, the majority of the individuals $(\mathrm{N}=27)$ had never participated, with no differences between the experimenttal and control groups $(\chi=1.3$, d.f. $=1, p=.31)$. The main characteristics of the participants are described in Table 1.

\section{Description of the Intervention}

The intervention consisted of 2 sessions per week of 45 minutes each for 16 weeks, over a period of roughly 5 months. It was presented to 7 groups of 4 - 5 self-sufficient older persons living in residential care facilities. The sessions were conducted by instructors, all of who had university degrees in physical education and sports-related fields and specialized in physical fitness training for older people (Ciairano et al., 2006). The set of activities was specifically designed for this research. The intervention protocol focused on three specific objectives: mobility, balance, and resistance strength. It was designed to gradually engage and interest the participants in a variety of different activities, by using both conventional and unconventional instruments (such as stools, sticks, clubs, hoops, balloons, foam balls, towels, paper cups, pins, bowls, paper tissues, scarves, and trays) and by emphasizing the playful side of said 
Table 1.

Characteristics of participants $(\mathrm{N})$.

\begin{tabular}{|c|c|c|c|c|c|}
\hline \multirow{3}{*}{ Variable } & \multirow{3}{*}{ Category } & \multicolumn{4}{|c|}{ Group } \\
\hline & & \multicolumn{2}{|c|}{ Control } & \multicolumn{2}{|c|}{ Experimental } \\
\hline & & $\mathrm{N}$ & $\%$ & $\mathrm{~N}$ & $\%$ \\
\hline \multirow{2}{*}{ Gender } & Female & 9 & 82 & 19 & 58 \\
\hline & Male & 2 & 18 & 14 & 42 \\
\hline \multirow{3}{*}{$\begin{array}{l}\text { Past participation } \\
\text { in physical } \\
\text { activities }\end{array}$} & No & 8 & 73 & 19 & 58 \\
\hline & Yes & 3 & 27 & 14 & 42 \\
\hline & Northern Italy & 10 & 91 & 30 & 91 \\
\hline \multirow{3}{*}{$\begin{array}{l}\text { Region of } \\
\text { provenience }\end{array}$} & Central Italy & l & l & 2 & 6 \\
\hline & Southern Italy & 1 & 9 & 1 & 3 \\
\hline & Never married & 1 & 9 & 6 & 18 \\
\hline \multirow{3}{*}{ Marital status } & Married & 1 & 9 & 7 & 21 \\
\hline & Widow/Widower & 9 & 82 & 17 & 52 \\
\hline & Divorced & 1 & 1 & 3 & 9 \\
\hline \multirow[t]{2}{*}{ Past job } & Manual labor & 10 & 91 & 21 & 64 \\
\hline & Non-manual labor & 1 & 9 & 12 & 36 \\
\hline \multirow[t]{2}{*}{$\begin{array}{l}\text { Level of } \\
\text { education }\end{array}$} & Only primary school & 9 & 82 & 24 & 73 \\
\hline & $\begin{array}{l}\text { More than primary } \\
\text { school }\end{array}$ & 2 & 18 & 9 & 27 \\
\hline Age & Mean (SD) & \multicolumn{2}{|c|}{$\begin{array}{c}85 \\
(6.6)\end{array}$} & \multicolumn{2}{|c|}{$\begin{array}{c}84.26 \\
(7.4)\end{array}$} \\
\hline
\end{tabular}

activities.

In addition, the personnel working in the facilities informed the instructors every day about each participant's condition, including minor physical problems, so that no potentially dangerous movements were required during the training sessions. Furthermore, special care was taken to provide the older persons with plenty of time to perform each movement, avoiding activities that could be perceived as too intense, embarrassing, or difficult.

\section{Procedure}

The 7 coaches who conducted the training program were all women, with a mean age of $29(\mathrm{SD}=4.4$; range $26-34)$. They all had university degrees in physical education and sportsrelated fields, and specializations in adapted physical education. The coaches were selected on the basis of their results in the university courses "Adapted Physical Activity" and "Health and Old Age". That is, we selected only those instructors who achieved a final grade higher than the 95th percentile of the grade distribution for these subjects. All the selected coaches agreed to participate in the study and received a small stipend for travel expenses incurred in order to conduct the physical activity program. The activity was recognized as part of their professional training.

We tested both the experimental and the control group with a battery of psychological and physical instruments, before and after the physical activity program. We performed biomechani- cal tests on hand-grip strength and individual finger-pinch strength for both hands. Individual finger-pinch strength was measured using a squeeze dynamometer, precision $.5 \mathrm{~kg}$ strength, in two different ways (Imrhan \& Loo, 1989): with the fleshy part of the index finger in opposition to the thumb; with the thumb pressing from above in opposition to the side of the index finger.

The two tests were performed with the individuals in a standard position, sitting and holding the instrument while their elbows rested on a table (Imrhan \& Rahman, 1994). A dynamometer was used to measure the grip strength of the entire hand, precision $1 \mathrm{~kg}$ strength (Imrhan \& Loo, 1989). We used a standard table (Imrhan \& Rahman, 1994) and a chair with an adjustable height so that the subjects sat with their forearms resting on the tabletop at a 90-degree angle to the body and kept their backs straight. The tests were performed individually, alternating between the left and right hand for both-hand strength and the finger pinch.

We also presented the coaches with a self-efficacy scale at the beginning of the physical activity program. The self-report questionnaire (taken from Caprara, 2001), made up of 22 items, was aimed at assessing the ability to positively influence the environment and prepare it for the introduction of a physical activity program for the elderly, the adoption of major sources of self-efficacy, as well as the ability to promote the physical activity program among the elderly ("How capable did you feel?" $1=$ Not at all, $2=$ A little, $3=$ Quite, $4=$ Very). We tested the reliability of the scale by means of Cronbach's $\alpha$ and we obtained a score of .93. We did not experience any particular problems while administering the instruments. For this study, we consider the coaches' self-efficacy to be the moderator.

\section{Analysis Strategy}

In order to verify our research hypothesis, we carried out non-parametric tests on independent and dependent samples. Non-parametric tests are used when there are uncertainties about the normalcy of distribution of the variables being investtigated, often due to small sample size.

To evaluate the effect of the physical activity program on the considered motor variables, we used the Mann-Whitney U test for independent samples. We then compared the post-test values of the experimental group and of the control group. The hypothesis that self-efficacy acts as a moderator was tested indirectly, due to the small sample size. First of all, we divided the experimental sample into two subgroups based on the self-efficacy score of their respective coaches: a group with low self-efficacy and a group with high self-efficacy. This was accomplished by calculating the median of the self-efficacy scale score of 74 (range $=22-88, \min =64, \max =85$ ). We found that 3 of the 7 coaches were at high self-efficacy, while the other 4 were at low self-efficacy.

Second, we performed the statistical analysis by using the Wilcoxon test for dependent samples. We compared the pre-test and post-test mean ranks of the motor variables' scores separately for the two experimental subgroups, the first included individuals who had worked under the supervision of a high self-efficacy instructor and the second included individuals who had worked under the supervision of a low self-efficacy instructor. This procedure was applied to both groups of instructtors (both high and low self-efficacy). We compared the $\mathrm{Z}$ scores of each of the two self-efficacy subgroups for each mo- 
tor variable under investigation in order to check whether the group of older persons supervised by high self-efficacy coaches displayed more significant post-test improvements than the group supervised by low self-efficacy instructors. All the non-parametric tests were carried out using the Monte Carlo methods and, to further support our theoretical hypotheses, we also performed an effect size analysis. All analyses were conducted using the SPSS version 18.0 statistical package.

\section{Results}

First of all, we verified whether participating in the physical activity program had positive effects on hand strength and the thumb-index pinch by comparing the post-test scores of the experimental group to those of the control group (Table 2). The data show that at the end of the physical activity program the experimental group displayed increased right-hand strength $(Z$ $=-2.082, p<.037$, effect size $=-.21)$ and left-hand strength $(\mathrm{Z}$ $=-2.055, p<.040$, effect size $=-.21)$ in comparison to the control group.

Concerning the thumb-index pinch, statistically significant differences emerged between the experimental group and the control group in relation to index-thumb strength in the right hand $(Z=-2.410, p<.016$, effect size $=-.24)$. No differences were detected between the two groups in relation to right hand thumb-index strength $(Z=-1.529, p<.126)$, left hand thumbindex strength $(\mathrm{Z}=-.446, p<.656)$, and left hand index-thumb strength $(Z=-1.827, p<.068)$.

As mentioned above, to verify the hypothesis that the coaches' self-efficacy acts as a moderator, we compared the pre-test and post-test values of the older persons coached by low self-efficacy instructors and those coached by high selfefficacy instructors. When analyzing right-hand strength (Table 3), we saw that at the end of the program the rank did not change for the group of older individuals coached by low selfefficacy instructors $(\mathrm{z}=-1.268, p=.227)$, whereas it changed for those coached by high self-efficacy instructors $(z=-2.074$, $p=.034$, effect size $=-.35$ ). The right hand thumb-index pinch values did not undergo any significant changes in the group coached by low self-efficacy instructors $(\mathrm{z}=-1.792, p=.084)$, while it changed in the group coached by high self- efficacy instructors $(z=-2.970, p=.002$, effect size $=-.46)$. The left hand thumb-index pinch values did not undergo any significant changes in the group coached by low self-efficacy instructors $(z$ $=-.159, p=.876)$, while it changed in the group coached by high self-efficacy instructors $(z=-2.474, p=.011$, effect size $=$ $-.37)$. The right hand index-thumb pinch values did not undergo any significant changes in the group coached by low self-efficacy instructors $(\mathrm{z}=-.079, p=.959)$, while it changed in the group coached by high self-efficacy instructors $(\mathrm{z}=$ $-2.371, p=.02$, effect size $=-.36$ ). Lastly, the left hand index-thumb pinch values did not undergo any significant changes in the group coached by low self-efficacy instructors ( $z$ $=-1.019, p=.329)$, while it changed in the group coached by high self-efficacy instructors $(z=-2.605, p=.007$, effect size $=$ $-.40)$.

\section{Discussion}

The objective of this study was to investigate how participation in a physical activity program affects the upper limb motor skills of a sample of elderly people living in residential care facilities in Piedmont, Italy. Moreover, it aimed at ascertaining if the coaches' level of perceived self-efficacy acts as a moderator on the motor skills, hand strength, and finger strength of the participants.

As for the first research hypothesis, we wanted to determine whether participating in a physical activity program can, in time, lead to improved hand strength. Several studies acknowledge the fact that palm grip strength is an important biomechanical parameter representative of overall muscle strength as well as an indicator of those clinical conditions that influence selfsufficiency/frailty in older persons (Ishizaki, Watanabe, Suzuki, Shibata, \& Haga, 2000; Michel-Pellegrino, Lia, Hewsona, Hogrel, \& Duchêne, 2009; Tainaka, Takizawa, Katamoto, \& Aoki, 2009). The data gathered through our investigation provide some interesting insight into this issue:

After completing the physical activity protocol, right and left

Table 2.

Results of the non-parametric test for independent samples. Difference between experimental and control group — median (Me), mean (M), standard deviation (SD), Z-value and $p$, effect size (ES) for the dependent variables.

\begin{tabular}{|c|c|c|c|c|c|c|c|c|c|c|c|c|c|c|c|c|}
\hline \multirow{3}{*}{ Dependent variables } & \multicolumn{8}{|c|}{ Pre-test } & \multicolumn{8}{|c|}{ Post-test } \\
\hline & \multicolumn{3}{|c|}{ Experimental } & \multicolumn{3}{|c|}{ Control } & \multirow{2}{*}{$\mathrm{Z}$} & \multirow{2}{*}{ ES } & \multicolumn{3}{|c|}{ Experimental } & \multicolumn{3}{|c|}{ Control } & \multirow{2}{*}{ Z } & \multirow{2}{*}{ ES } \\
\hline & $\mathrm{Me}$ & M & $\mathrm{SD}$ & $\mathrm{Me}$ & $\mathrm{M}$ & $\mathrm{SD}$ & & & $\mathrm{Me}$ & M & $\mathrm{SD}$ & $\mathrm{Me}$ & M & SD & & \\
\hline Right-hand strength & 3 & 4.1 & 4 & 0 & 2.8 & 4.5 & $\begin{array}{c}\mathrm{Z}=-1.861 \\
p<.063\end{array}$ & / & 3 & 4.7 & 5.4 & 0 & 2.1 & 4.4 & $\begin{array}{c}\mathrm{Z}=-2.082 \\
p<.037\end{array}$ & -.21 \\
\hline Left-hand strength & 3.5 & 4.2 & 5.1 & 0 & 2.1 & 3.6 & $\begin{array}{c}\mathrm{Z}=-2.259 \\
p<.024\end{array}$ & -.23 & 2 & 4.3 & 6.5 & 0 & 1.4 & 2.8 & $\begin{array}{c}\mathrm{Z}=-2.055 \\
p<.040\end{array}$ & -.21 \\
\hline Right thumb-index strength & 4 & 4.2 & 1.1 & 3.5 & 4.8 & 2 & $\begin{array}{c}Z=-.059 \\
p<.953\end{array}$ & I & 4 & 4.7 & 2.1 & 3 & 4.1 & 2.5 & $\begin{array}{c}\mathrm{Z}=-1.529 \\
p<.126\end{array}$ & I \\
\hline Left thumb-index strength & 4 & 3.9 & 1.9 & 3.5 & 3.9 & 1.3 & $\begin{array}{c}\mathrm{Z}=-.079 \\
p<.937\end{array}$ & / & 4 & 4.1 & 1.9 & 3.5 & 3.7 & 1 & $\begin{array}{c}\mathrm{Z}=-.446 \\
p<.656\end{array}$ & l \\
\hline Right index-thumb strength & 4 & 3.9 & 1.6 & 2.5 & 3.3 & 2.1 & $\begin{array}{c}\mathrm{Z}=-1.512 \\
p<.130\end{array}$ & l & 4 & 4 & 1.7 & 2 & 3 & 2.6 & $\begin{array}{c}\mathrm{Z}=-2.410 \\
p<.016\end{array}$ & -.24 \\
\hline Left index-thumb strength & 3.5 & 3.8 & 1.8 & 3 & 3.3 & 1.6 & $\begin{array}{c}\mathrm{Z}=-.939 \\
p<.348\end{array}$ & / & 3.5 & 3.7 & 1.7 & 2.5 & 2.8 & 1.6 & $\begin{array}{c}\mathrm{Z}=-1.827 \\
p<.068\end{array}$ & l \\
\hline
\end{tabular}


Table 3.

Results of the non-parametric test for dependent samples. Pre- and post-test difference for older persons with low and high self-efficacy instructorsmedian (Me), mean (M), standard deviation (SD), Z-value and p, effect size (ES) for the dependent variables.

\begin{tabular}{|c|c|c|c|c|c|c|c|c|c|c|c|c|c|c|c|c|}
\hline \multirow{4}{*}{ Dependent variables } & \multicolumn{8}{|c|}{ Experimental } & \multicolumn{8}{|c|}{ Experimental } \\
\hline & \multicolumn{8}{|c|}{ Low Self-efficacy } & \multicolumn{8}{|c|}{ High Self-efficacy } \\
\hline & \multicolumn{3}{|c|}{ Pre-test } & \multicolumn{3}{|c|}{ Post-test } & \multirow{2}{*}{$\mathrm{Z}$} & \multirow{2}{*}{ ES } & \multicolumn{3}{|c|}{ Pre-test } & \multicolumn{3}{|c|}{ Post-test } & \multirow{2}{*}{ Z } & \multirow{2}{*}{ ES } \\
\hline & $\mathrm{Me}$ & M & $\mathrm{SD}$ & $\mathrm{Me}$ & $\mathrm{M}$ & SD & & & $\mathrm{Me}$ & $\mathrm{M}$ & SD & $\mathrm{Me}$ & $\mathrm{M}$ & SD & & \\
\hline Right-hand strength & 4 & 3.5 & 2.6 & 0 & 3.5 & 6.3 & $\begin{array}{c}\mathrm{Z}=-1.268 \\
p<.227\end{array}$ & I & 2 & 4.7 & 4.8 & 5.5 & 5.6 & 4.4 & $\begin{array}{c}\mathrm{Z}=-2.074 \\
p<.034\end{array}$ & -.35 \\
\hline Left-hand strength & 3.5 & 3 & 2.5 & 0 & 3.4 & 6.8 & $\begin{array}{c}\mathrm{Z}=-.424 \\
p<.751\end{array}$ & I & 3.5 & 5.2 & 6.5 & 3 & 5 & 6.3 & $\begin{array}{c}\mathrm{Z}=-.493 \\
p<.661\end{array}$ & / \\
\hline Right thumb-index strength & 3 & 3.7 & 2.1 & 4 & 4.8 & 2.2 & $\begin{array}{c}\mathrm{Z}=-1.792 \\
p<.084\end{array}$ & / & 4.3 & 4.6 & 1.8 & 4.5 & 4.6 & 2 & $\begin{array}{c}\mathrm{Z}=-2.970 \\
p<.002\end{array}$ & -.46 \\
\hline Left thumb-index strength & 3.8 & 4 & 1.9 & 4 & 4 & 2.1 & $\begin{array}{c}\mathrm{Z}=-.159 \\
p<.876\end{array}$ & / & 4 & 3.8 & 1.9 & 4 & 4 & 1.8 & $\begin{array}{c}\mathrm{Z}=-2.474 \\
p<.011\end{array}$ & -.37 \\
\hline Right index-thumb strength & 4 & 4.1 & 1.6 & 4 & 4.2 & 1.7 & $\begin{array}{c}\mathrm{Z}=-.079 \\
p<.329\end{array}$ & I & 3.8 & 3.7 & 1.6 & 4 & 3.9 & 1.8 & $\begin{array}{c}\mathrm{Z}=-2.371 \\
p<.02\end{array}$ & -.36 \\
\hline Left index-thumb strength & 4 & 4.4 & 2.1 & 3.5 & 3.7 & 1.9 & $\begin{array}{c}\mathrm{Z}=-1.019 \\
p<.329\end{array}$ & I & 3 & 3.3 & 1.4 & 3.5 & 3.6 & 1.6 & $\begin{array}{c}\mathrm{Z}=-\mathbf{2 . 6 0 5} \\
p<.007\end{array}$ & -.40 \\
\hline
\end{tabular}

hand strength functions improved in the experimental group, but the same did not happen in the control group. Hence, hand strength seems to have been influenced by the multi-modal exercises (Baker et al., 2007) included in the physical activity protocol, which comprised of aerobic, balance, flexibility, and resistance-strength activities with the use of small instruments. Research performed on samples of older persons of both genders with a mean age of 80 has proven that resistance training programs lasting for 12 weeks with 2 sessions a week can increase muscle strength (Sullivan, Roberson, Smith, Price, \& Bopp, 2007; Helbostad, Sletvold, \& Moe-Nilssen, 2004). Coherent with their findings, the results of our research point out that simple physical activity programs can activate/reactivate motor functions in older elderly and help preserve the strength ranges needed to be able to lead an independent life for as long as possible.

We also wanted to determine if the older persons who participated in the physical activity program displayed improved right and left hand finger functions in terms of index-thumb and thumb-index pinch. The data gathered through our investigation did not differ from that found in the literature about the older population (Keogh et al., 2007; Ranganathan, Siemionow, Saghal, \& Yue, 2001).

Our research questions also concerned the coaches' level of perceived self-efficacy and their ability to act as moderator on hand and finger strength. As hypothesized, there seems to be a relationship between motor functioning and the level of selfefficacy. Our results confirm that the coaches' level of perceived self-efficacy has a strong influence on successful participation in a physical activity program, which leads participants to continue their training and benefit from the re-activation of their motor skills. As our analysis proves, hand and finger strength results increase greatly in the groups coached by instructors with a high level of perceived self-efficacy. Hence, instructors with a higher level of self-efficacy seem to be more skilled in managing the variables and in implementing the adjustments needed to work with small groups of older elderly individuals. In particular, they seem to be able to detect those aspects that can act as barriers to motivation (Schutzer \& Graves, 2004) and to the successful taking up and continuation of a physical activity program (McAuley, Morris, Motl, Hu, Konopack, \& Elavsky, 2007).

The coach's trust in his/her skills to manage the learning process and his/her ability to successfully deal with decisions about the targets the students, in our case the older persons, can achieve (Bandura, 1997) greatly influences the performance of those receiving motor or sports training (Horn, 2008). High self-efficacy coaches are aware of the aims of the research protocol, know how important it is to meet deadlines so that the activity can be carried out in compliance with the instructions received, and apply the protocol rigorously. Moreover, they possess suitable teaching skills to successfully lead their group and to influence the development of a positive attitude towards physical activity (Feltz, Chase, Moritz, \& Sullivan, 1999). Therefore, the level of self-efficacy possessed by each instructor is an important variable that affects motor results in groups of older elderly individuals, just like it does in the case of high-level athletes.

The limitations of our research are mainly linked with: the small sample size (although the participants actually mirror the situation in Italian residential care facilities) and the absence of follow-up sessions (to determine if the improvements were permanent or if booster sessions were needed.)

In spite of the above, some stimulating observations can be drawn from our study. Firstly, physical activity can positively influence the preservation/improvement of hand and finger strength through specific training that includes targeted strength exercises. If hand function decreases with aging, individuals are destined to progressively lose their autonomy in managing the daily activities that require strength and dexterity in manipulating handheld objects, which are fundamental for eating, drinking, and looking after oneself (Carmeli et al., 2003). An individual's independence in daily activities decreases progressively and unevenly also in relation to functionality deficits: Eating, dressing, and looking after personal hygiene are related to good upper-limb functioning, whereas going to the bathroom 
autonomously depends on good lower-limb functioning (Huang et al., 2010). It is, therefore, necessary to design interventions for the preservation of autonomy in daily activities, by implementing protocols to limit the loss of - rather than to improve - motor skills in older elderly.

Another observation that can be drawn from our research regards the issue of moderation, an aspect which has been mostly overlooked in the literature about samples of older elderly. Understanding moderation effects on the efficacy of targeted physical activity programs will have a positive influence on the promotion of independence and health among the elderly living in residential care facilities.

It is particularly important to investigate the role of those who are conducting physical activity programs for the older elderly, since this can help design appropriate intervention protocols that take into account the specific characteristics of the targeted age bracket (Martens, 2004). As already pointed out in our previous research (Ciairano, Musella, Gemelli, Liubicich, Rabaglietti, \& Roggero, 2006), a good coach must possess a range of skills that address the individual as a whole-i.e. skills concerning teaching techniques and communication, the management of variables deriving from the intervention's context, and the protocols designed for each participant - based on individual needs and potential. Hence, the presence of suitably trained professional coaches will add value to physical activity programs, which will play a crucial role in preserving the independence of older persons living in residential care facilities.

\section{Acknowledgements}

The authors acknowledge Regione Piemonte, Assessorato Ricerca, Innovazione e Sviluppo Bando Scienze Umane 2009, for their contribution to this ACT ON AGING pilot study.

\section{REFERENCES}

A.I.P. [Italian Association of Psychology] (1997) Codice Etico della ricerca psicologica [Ethical code for psychological research]. Roma, IT: AIP. Accessed 6 August 2009.

http://www.mopi.it/docs/cd/aipcode.pdf

American College of Sports Medicine, (2000). ACSM's guidelines for exercise testing and prescription (6th ed.). Baltimore: Williams \& Wilking.

Baker, M. K., Atlantis, E., \& Fiatarone Singh, M. A. (2007). Multimodal exercise programs for older adults. Age and Ageing, 36, 375381. doi:10.1093/ageing/afm054

Banchero (2009). L'assistenza agli anziani non autosufficienti in Italia. Rapporto 2009 a cura di N.N.A. (Network Non Autosufficienza). Rapporto promosso dall'IRCSS-INCRA per l'Agenzia nazionale per l'invecchiamento.

Bandura, A. (1997). Self-Efficacy: The exercise of control. New York: Freedman and Company.

Bharucha, A. J., Pandav, R., Shen, C., Dodge, H. H., \& Ganguli, M. (2004). Predictors of nursing facility admission: A 12-year epidemicological study in the United States. Journal of the American Geriatrics Society, 52, 434-439.

Booth, M. L., Owen, N., Bauman, A., Clavisi, O., \& Leslie, E. (2000). Social-cognitive and perceived environment influences associated with physical activity in older Australians. Preventive Medicine, 31, 15-22. doi:10.1006/pmed.2000.0661

Bowling, A., \& Grundy, E. (1997). Activities of daily living. Changes in functional ability in three samples of elderly and very elderly people. Age and Ageing, 26, 107-114. doi:10.1093/ageing/26.2.107

Caprara, G. V. (2001). La valutazione dell'autoefficacia. Costrutti e strumenti. Trento: Erickson.
Caprara, G. V., Barbaranelli, C., Steca, P., \& Malone, P. S. (2006). Teachers' self-efficacy beliefs as determinants of job satisfaction and students' academic achievement: A study at the school level. Journal of School Psychology, 44, 473-490. doi:10.1016/j.jsp.2006.09.001

Carmeli, E., Patish, H., \& Coleman, R. (2003). The aging hand. Journal of Gerontology Series A Biological Sciences Medical Sciences, 58M, 146-152. doi:10.1093/gerona/58.2.M146

Ciairano, S., Liubicich, M. E., \& Rabaglietti, E. (2010). The effects of a physical activity program on the psychological wellbeing of older people in a residential care facility: An experimental study. Ageing \& Society, 30, 609-626. doi:10.1017/S0144686X09990614

Ciairano, S., Musella, G., Gemelli, F., Liubicich, M., Rabaglietti, E., \& Roggero, A. (2006). Progettazione degli interventi di promozione dell'attività motoria per gli anziani e formazione degli istruttori: Punti di forza e criticità. Giornale Italiano di Psicologia dello Sport, $1,13-21$.

Ciairano, S., Musella, G., Gemelli, F., Liubicich, M. E., Rabaglietti, E., \& Roggero, A. (2006). Un intervento di promozione dell'attività motoria e la salute fisica e psicologica degli anziani all'interno di una residenza: valutazione di processo e di risultato. Giornale Italiano di Psicologia dello Sport, 1, 3-11.

Cole, K.J. (2006). Age-related directional bias of fingertip force. EXperimental Brain Research, 175, 285-291. doi:10.1007/s00221-006-0553-0

Costa, G., Migliardi, A., \& Gnavi, R. (2006). Verso un profilo di salute [Towards a Profile of Health]. Servizio Centrale Comunicazione, Città di Torino, Turin, Italy.

Desrosiers, J., Hebert, R., Bravo, G., \& Dutil, E. (1995) Upper-extremity motor co-ordination of healthy elderly people. Age and Ageing. 24, 108-112. doi:10.1093/ageing/24.2.108

Dye, C., \& Wilcox, S. (2006). Beliefs of low-income and rural older women regarding physical activity: You have to want to make your life better. Women \& Health, 43, 115-134. doi:10.1300/J013v43n01 07

Feltz, D. L., Chase, M. A., Moritz, S. E., \& Sullivan, P. J. (1999). A conceptual model of coaching efficacy: Preliminary investigation and instrument development. Journal of Educational Psychology, 4, 765 776. doi:10.1037/0022-0663.91.4.765

Ferrucci, L., Guralnik, J. M., Studenski, S., Fried, L. P., Culter, G. B. Jr., \& Walston, J. D. (2004). Designing randomized, controller trials aimed at preventing or delaying functional decline and disability in frail, older persons: A consensus report. Journal of the American Geriatric Society, 52, 625-634. doi:10.1111/j.1532-5415.2004.52174.x

Folstein, M., Folstein, S., \& McHugh, P. R. (1975). Mini-Mental State: A practical method for grading the cognitive state of patients for the clinician. Journal of Psychiatric Research, 12, 189-198. doi:10.1016/0022-3956(75)90026-6

Fried, L. P., Ferrucci, L., Darer, J., Williamson, J. D., \& Andreson, G. (2004). Untangling the concepts of disability, frailty, and comorbidity: Implications for improved targeting and care. Journal of Gerontology Series A Medical Science, 59, 255-263.

Gaugler, J. E., Duval, S., Anderson, K. A., \& Kane, L. R. (2007). Predicting nursing home admission in the U.S.: A meta-analysis. Biomedcentral Geriatrics, 7, 1-14.

Gill, T. M., Baker, D. I., Gottschalk, M., Peduzzi, P. N., Allore, H., \& Van Ness, P. H. (2004). A prehabilitation program for the prevention of functional decline: Effect on higher-level physical function. Archives of Physical Medicine and Rehabilitation, 85, 1043-1049. doi:10.1016/j.apmr.2003.10.021

Gordon, L. M. (2001). Higher teacher efficacy as a marker of teacher effectiveness in the domain of classroom management. Paper presented at the annual meeting of the California Council on Teacher Education, San Diego, CA.

Guralnik, J. M., \& Simonsick, E. M. (1993). Physical disability in older Americans. The Journal of Gerontology, 48, 3-10.

Guralnik, J. M., Alecxih, L., Branch, L. G., \& Wiener, J. M. (2002). Medical and long-term care costs when elderly become more dependent. American Journal of Public Health, 92, 1244-1245. doi:10.2105/AJPH.92.8.1244 
Hackel, M. E., Wolfe, G. A., Bang, S. M., \& Canfield, J. S. (1992). Changes in hand function in the aging adult as determined by the Jebsen test of hand function. Physical Therapy, 72, 373-378.

Hardy, S. E., Dubin, J. A., Holford, T. R., \& Gill, T. M. (2005). Transitions between states of disability and independence among older persons. American Journal of Epidemiology, 161, 575-584. doi:10.1093/aje/kwi083

Hauer, K., Becker, C. U., \& Beyer, N. (2006). Effectiveness of physical training on motor performance and fall prevention in cognitively impaired older persons. American Journal of Physical Medicine \& Rehabilitation, 85, 847-857. doi:10.1097/01.phm.0000228539.99682.32

Helbostad, J. L., Sletvold, O., \& Moe-Nilssen, R. (2004). Effects of home exercises and group training on functional abilities in homedwelling older persons with mobility and balance problems. Aging Clinical and Experimental Research, 16, 113-121.

Horn, T. S. (2008). Coaching effectiveness in the sport domain. In T. S. Horn (Ed.), Advances in Sport Psychology (3rd ed., pp. 239-267) Champaign, IL: Human Kinetics.

Huang, W. W., Perera, S., VanSwearingen, J., \& Studenski, S. (2010). Performance measures predict onset of activity of daily living difficulty in community-dwelling older adults. Journal of the American Geriatric Society, 58, pp. 844-852. doi:10.1111/j.1532-5415.2010.02820.x

Imhran, S. N., \& Loo, C. H. (1989). Trends in finger pinch strength in children, adults, and the elderly. Human Factors, 31, 689-701.

Imhran, S. N., \& Rahman, R. (1994). The effects of pinch width on pinch strengths of adult males using realistic pinch-handle coupling. International Journal of Industrial Ergonomics, 16, 123-134.

Ishizaki, T., Watanabe, S., Suzuki, T., Shibata, H., \& Haga, H. (2000). Predictors for functional decline among nondisabled older Japanese living in a community during a 3-year follow-up. Journal of the American Geriatric Society, 48, 1424-1429.

Jessup, J. V., Horne, C., Vishen, R. K., \& Wheeler, D. (2003). Effects of exercise on bone density, balance, and self-efficacy in older women. Biological Research for Nursing, 4, 171-180. doi: $10.1177 / 1099800402239628$

Jina, S. Y. (2002). Teacher characteristics as predictors of teacherstudent relationships: Stress, negative affect, and self-efficacy. Social Behaviour and Personality: An International Journal, 30, 485-493. doi:10.2224/sbp.2002.30.5.485

Kallinen, M., Sipila, S., Alen, M., \& Suominen, H. (2002). Improving cardiovascular fitness by strength or endurance training in women aged 76-78 years. A population-based, randomized study. Aging Clinical Experimental Research, 16, 113-121.

Keogh, J.W., Morrison, S., \& Barrett, R. (2007). Strength training improves the tri-digit finger-pinch force control of older adults. Archive Physiology Medicine Rehabilitation, 88, 1055-1063. doi:10.1016/j.apmr.2007.05.014

Lavile d'Epinay, C., \& Spini, D. (2007). Le grand age. Un domaine de recherché recent. Gérontologie et Société, 123, 31-54.

Lavile d'Epinay, C., Pin, S., \& Spini, D. (2001). Présentation de Swilso-o, une étude longitudinale suisse sur la grand age. L'exemple de la dynamique de la santé fonctionnelle. L'Année Gérontologique, 15, 78-96.

Lee, L. L., Arthur, A., \& Avis, M. (2008). Using self-efficacy theory to develop interventions that help older people overcome psychological barriers to physical activity: A discussion paper. International Journal of Nursing Studies, 45, 1690-1699.

doi:10.1016/j.ijnurstu.2008.02.012

Lidz, C., Fisher, L., \& Arnold, R. M. (1992). The erosion of autonomy in long-term care. New York: Oxford University Press.

Liubicich, M. E., Magistro, D., Candela, F., Rabaglietti, E., \& Ciairano S., (2012) Physical activity and mobility function in elderly people living in residential care facilities. "Act on Aging": A pilot study. Advances in Physical Education, 2.

Lubitz, J., Cai, L., Kramarow, E., \& Lentzner, H. (2003). Health, life expectancy, and health care spending among the elderly. The New England Journal of Medicine, 349, 1048-1055. doi:10.1056/NEJMsa020614
Malbut, K. E., Dinan, S., \& Young, A. (2002). Aerobic training in the "oldest old": The effect of 24 weeks of training. Age and Ageing, 31, 255-260. doi:10.1093/ageing/31.4.255

Malbut-Shennan, K., \& Young, A. (1999). The physiology of physical performance and training in old age. Coronary Artery Diseases, 10, 37-42. doi:10.1097/00019501-199901000-00007

Martens, R. (2004). Successful coaching. Human Kinetics, Champaign, IL.

Martin, L. J., Sale, M. V., \& Semmler, J. G. (2005). Age-related differences in corticospinal control during functional isometric contractions in left and right hands. Journal of Applied Physiology, 9, 14831493.

Mathiowetz, V., Weber, K., Kashman, N., \& Volland, G. (1985) Adult norms for the nine hole peg test of finger dexterity. Occupational Therapy Journal of Research, 5, 24-37.

McAuley E., Morris, K. S., Motl, R. W., Hu, L., Konopack, J. F., \& Elavsky, S. (2007). Long-term follow-up of physical activity behaviour in older adults. Health Psychology, 26, 375-380. doi:10.1037/0278-6133.26.3.375

Michel-Pellegrino, V., Lia, K., Hewsona, D., Hogrel, J. Y., \& Duchêne, J. (2009). Techniques d'évaluation à domicile de la qualité de l'équilibre et de la force de préhension chez la personne âgée en perte d'autonomie. Elsevier Masson, IRBM, 30, 262-267. doi:10.1016/j.irbm.2009.10.010

Millàn-Calenti, J. C., Tubio, J., Pita-Fernàndez, S., Gonzàles-Abraldes, I., Lorenzo, T., Fernàndez-Arruty, T., \& Maseda, A. (2010). Prevalence of functional disability in activities of daily living (ADL), instrumental activities of daily living (IADL) and associated factors, as predictors of morbidity and mortality. Archives of Gerontology and Geriatrics, 50, 306-310. doi:10.1016/j.archger.2009.04.017

Nakagawa, K., Inomata, N., Konno, Y., Nakasawa, R., Hagiwara K., \& Sakamoto, M. (2008). The characteristic of a simple exercise program under the instruction of physiotherapists for general elderly people and frail elderly people. Journal of Physical Therapy Science, 20, 197-203. doi:10.1589/jpts.20.197

Netz, Y., Wu, M.-J., Becker, B. J., \& Tenenbaum, G. (2005). Physical activity and psychological well-being in advance age: A metaanalysis of intervention studies. Psychology and Aging, 2, 272-284. doi:10.1037/0882-7974.20.2.272

Oliveira, M. A., Shim, J. K., Loss, J. F., Petersen, R. D., \& Clark, J. E. (2006). Effect of kinetic redundancy on hand digit control in children with DCD. Neuroscience Letters, 410, 42-46. doi:10.1016/j.neulet.2006.09.065

Paterson, D. H., Govindasamy, D., Vidmar, M., Cunningham, D. A., \& Koval, J. J. (2004). Longitudinal study of determinants of dependence in an elderly population. Journal of American Geriatrics Society, 52, 1632-1638. doi:10.1111/j.1532-5415.2004.52454.x

Pearlin, L. I., \& Mullan, J. T. (1992). Loss and stress in aging. In M. L. Wykle, E. Kahara, \& J. Kowal (Eds.) Stress and health among the elderly (pp. 117-132). New York: Springer.

Peri, K., Kerse N., Robinson E., Parsons M., Parsons J., \& Latham N. (2008). Does functionally based activity make a difference to health status and mobility? A randomized controlled trial in residential care facilities (The Promoting Independent Living Study; PILS). Age and Ageing, 37, 57-63. doi:10.1093/ageing/afm135

Pianta, R. C., \& Stuhlman, M. W. (2004). Teacher-child relationships and children's success in the first year of the school. School Psychology Review, 33, 444-458.

Potter, N. L., Kent, R. D., Lindstrom, M. J., \& Lazarus, J. A. (2006). Power and precision grip force control in three-to-five-year-old children: Velocity control precedes amplitude control in development. Experimental Brain Research, 172, 246-260. doi:10.1007/s00221-005-0322-5

Rabaglietti, E., Roggero, A., Mosca Barberis, P., \& Ciairano, S. (2003). Le convinzioni di autoefficacia nel recupero degli infortuni: Una ricerca longitudinale. Giornale Italiano di Psicologia dello Sport, 3, $57-61$.

Ranganathan, V. K., Siemionow, V., Saghal, V., \& Yue, G. (2001). Effects of aging on hand function. Journal of American Geriatric 
Society, 49, 1478-1484. doi:10.1046/j.1532-5415.2001.4911240.x

Rantanen, T., Volpato, S., Ferrucci, L., Heikkinen, E., Fried, L. P., \& Guralnik, J. M. (2003). Handgrip strength and cause-specific and total mortality in older disabled women: Exploring the mechanism. Journal of American Geriatric Society, 51, 636-641. doi:10.1034/j.1600-0579.2003.00207.x

Rejeski, W. J., \& Mihalko, S. L. (2001). Physical activity and quality of life in older adults. Journal of Gerontology Series A Biological Sciences Medical Sciences, 56, 23-35. doi:10.1093/gerona/56.suppl 2.23

Rivkin, S. G., Hanushek, E. A., \& Kain, J. F. (2005). Teachers, schools, and academic achievement. Econometrica, 73, 417-458. doi:10.1111/j.1468-0262.2005.00584.x

Ross, J.A. (1992). Teacher efficacy and the effects of coaching on student achievement. Canadian Journal of Education, 17, 51-65. doi: $10.2307 / 1495395$

Scherder, E., Dekker, W., \& Eggermont, L. (2008). Higher-level hand motor function in aging and (preclinical) dementia, its relationship with (instrumental) activitiesof daily life-A mini-review. Gerontology, 54, 333-341. doi:10.1159/000168203

Schutzer, K., \& Graves, B.S. (2004). Barriers and motivations to exercise in older adults. Preventive Medicine, 39, 1056-1061. doi:10.1016/j.ypmed.2004.04.003

Shinohara, M., Latash, M.L., \& Zatsiorsky, V.M. (2003). Age effects on force produced by intrinsic and extrinsic hand muscles and finger interaction during MVC tasks. Journal of Applied Physiology, 95, 1361-1369.

Shinohara, M., Scholz, J.P., Zatsiorsky, V.M., \& Latash, M.L. (2004). Finger interaction during accurate multi-finger force production tasks in young and elderly persons. Experimental Brain Research, 156, 282-292. doi:10.1007/s00221-003-1786-9

Snih, S., Markides, K.S., Ostir, G.V., Ray, L., \& Goodwin, J. (2003). Predictors of recovery in activities of daily living among disabled older Mexican-Americans. Aging Clinical Experimental Research, 15, 315-320.

Snih, S., Markides, K.S., Ottenbacher, K.J., \& Raij M.A. (2004). Hand grip strength and incident ADL disability in elderly MexicanAmericans over a seven-year period. Aging Clinical Experimental
Research, 16, 481-486.

Stenzelius, K., Westergreen, A., Thorneman, G., \& Rahm Hallberg, I. (2005). Patterns of health complaints among people $75+$ in relation to quality of life and need of help. Archives of Gerontology and Geriatrics, 40, 85-102. doi:10.1016/j.archger.2004.06.001

Sullivan, D.H., Roberson, P.K., Smith, E.S., Price, J.A., \& Bopp, M.M. (2007). Effects of muscle strength training and megestrol acetate on strength, muscle mass, and function in frail older people. Journal of the American Geriatric Society, 55, 20-28. doi:10.1111/j.1532-5415.2006.01010.x

Taekema, D.G., Gussekloo, J., Maier, A.B., Westendorp, R.G.J., \& De Craen, A.J.M. (2010). Handgrip strength as a predictor of functional, psychological and social health. A prospective population-based study among the oldest old. Age and Ageing, 39, 331-337. doi:10.1093/ageing/afq022

Tainaka, K., Takizawa, T., Katamoto, S., \& Aoki, J. (2009). Six-year prospective study of physical fitness and incidence of disability among community-dwelling Japanese elderly women. Geriatric and Gerontology International, 9, 21-28. doi:10.1111/j.1447-0594.2008.00492.x

Topinkovà, E. (2008). Aging, disability and frailty. Annals of Nutrition \& Metabolism, 52, 6-11. doi:10.1159/000115340

van der Bij, A.K., Laurant, M.G.H., \& Wensing, M. (2002). Effectiveness of physical activity interventions for older adults. American Journal of Preventive Medicine, 22, 120-133. doi:10.1016/S0749-3797(01)00413-5

Vaillancourt, D.E., Larsson, L., \& Newell, K. M. (2003). Effects of aging on force variability, single motor unit discharge patterns, and the structure of 10, 20, and $40 \mathrm{~Hz}$ EMG activity. Neurobiology of Aging, 24, 25-35. doi:10.1016/S0197-4580(02)00014-3

Wilcox, S., Tudor-Locke, C.E., \& Ainsworth, B.E. (2002). Physical activity patterns, assessment, and motivation in older adults. In R. J. Shephard (ed.), Gender, physical activity and aging (pp. 13-39). Boca Raton: CRC Press.

World Health Organization (2002). Active ageing: A policy framework. Ageing and Life Course Team, Non-Communicable Disease Prevention and Health Promotion Department. Geneva: WHO. 